\title{
Role of Transisthmus Conduction Intervals in Predicting Bidirectional Block after Ablation of Typical Atrial Flutter
}

\author{
HAKAN ORAL, M.D., CHRISTIAN STICHERLING, M.D., HIROSHI TADA, M.D., \\ STEVEN P. CHOUGH, M.D., ROBERT L. BAKER, M.D., KRISTINA WASMER, M.D., \\ FRANK PELOSI JR., M.D., BRADLEY P. KNIGHT, M.D., FRED MORADY, M.D., \\ and S. ADAM STRICKBERGER, M.D.
}

From the Division of Cardiology, Department of Internal Medicine, University of Michigan, Ann Arbor, Michigan

Isthmus Block During Atrial Flutter Ablation. Introduction: Complete bidirectional cavotricuspid isthmus block is the endpoint for ablation of typical atrial flutter. The purpose of this study was to determine whether the extent of prolongation of the transisthmus interval after ablation predicts complete bidirectional block.

Methods and Results: Fifty-seven consecutive patients underwent 60 ablation procedures for isthmus-dependent atrial flutter. The clockwise and counterclockwise transisthmus intervals were determined before and after ablation during pacing from the low lateral right atrium and the coronary sinus. Bidirectional block was achieved with ablation in $55(96 \%)$ of 57 patients. The transisthmus intervals before ablation and after complete transisthmus block were $100.3 \pm 21.1$ msec and 195.8 \pm 30.1 msec, respectively, in the clockwise direction $(P<0.0001)$, and $98.2 \pm 24.7$ msec and $185.7 \pm 33.9$ msec, respectively, in the counterclockwise direction $(P<0.0001)$. An increase in the transisthmus interval by $\mathbf{2 5 0 \%}$ in both directions after ablation predicted complete bidirectional block with $100 \%$ sensitivity and $80 \%$ specificity. The positive and negative predictive values were $89 \%$ and $100 \%$, respectively. The diagnostic accuracy of a $\geq 50 \%$ prolongation in the transisthmus interval was $92 \%$.

Conclusion: Prolongation of the transisthmus interval by $\geq 50 \%$ in the clockwise and counterclockwise directions is associated with a high degree of diagnostic accuracy and an excellent negative predictive value in determining complete bidirectional transisthmus block. This may be a useful and simple adjunctive criterion for assessment of complete transisthmus conduction block. ( $J$ Cardiovasc Electrophysiol, Vol. 12, pp. 169-174, February 2001)

supraventricular tachycardia, radiofrequency, block

\section{Introduction}

Complete bidirectional cavotricuspid isthmus block is the endpoint for radiofrequency catheter ablation of isthmus-dependent atrial flutter. ${ }^{1-13}$ Several techniques, including detailed atrial activation mapping and identification of widely split double potentials along the ablation line, have been used to determine the presence of complete bidirectional isthmus block. ${ }^{6-13}$ The purpose of this study was to determine how accurately a simple technique of measuring the extent of prolongation in the transisthmus conduction interval during pacing predicts

Address for correspondence: Hakan Oral, M.D., Division of Cardiology, B1F245, University of Michigan Hospital, 1500 E. Medical Center Drive, Ann Arbor, MI 48109-0022. Fax: 734-936-7026; E-mail: oralh@umich.edu

Manuscript received 21 September 2000; Accepted for publication 20 October 2000. the presence or absence of complete bidirectional isthmus block.

\section{Methods}

\section{Patient Characteristics}

The subjects of this study were 57 consecutive patients who underwent 60 radiofrequency catheter ablation procedures for isthmus-dependent atrial flutter at the University of Michigan Medical Center. There were 44 men and 13 women (mean age $58 \pm 13$ years, range 35 to 86) with left ventricular ejection fraction of $0.48 \pm$ 0.11 (range 0.20 to 0.60 ). Structural heart disease was present in 21 patients. This included coronary artery disease in 13 patients, nonischemic cardiomyopathy in 5 , valvular heart disease in 2 , and repaired atrial septal defect in 1 . Among the 57 patients, concomitant antiarrhythmic medications at the time of the ablation procedure included amiodarone in 20 patients, a Class I anti- 


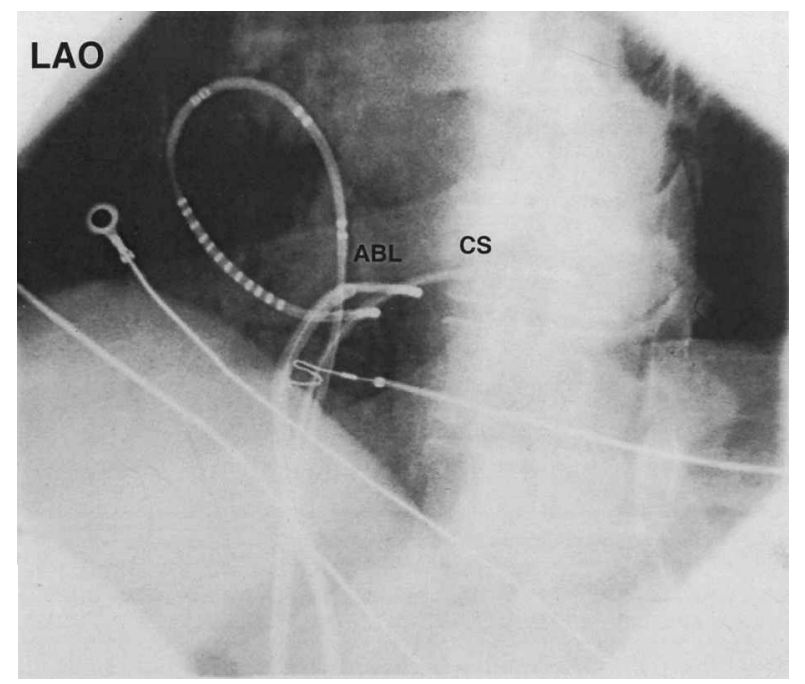

Figure 1. Left anterior oblique (LAO) $45^{\circ}$ fluoroscopic view of catheter positions during atrial flutter ablation. A duodecapolar halo catheter is positioned along the tricuspid annulus and along the cavotricuspid isthmus. A quadripolar catheter is positioned in the coronary sinus (CS) for pacing. An ablation catheter $(A B L)$ is positioned across the isthmus.

arrhythmic agent in 12 , sotalol in 3 , digoxin in 6 , a calcium channel blocker in 4 , and a beta blocker in 10 . There were no statistically significant differences in transisthmus intervals between patients who were taking antiarrhythmic agents and those who were not.

\section{Electrophysiologic Procedure}

Informed consent was obtained from all patients. A quadripolar catheter (EP Technologies, Inc., San Jose, CA, USA) was positioned within the proximal coronary sinus. A duodecapolar halo catheter (Daig Corporation, Minnetonka, MN, USA) was positioned along the tricuspid annulus (Fig. 1). A 4-mm tip catheter (EP Technologies) was used for mapping the isthmus and delivering radiofrequency energy. Electrograms were filtered at bandpass settings of 30 to $500 \mathrm{~Hz}$ and recorded digitally (EPMed Systems, Inc., Mount Arlington, NJ, USA). Pacing was performed from the coronary sinus or the low right atrium through the halo catheter with an external stimulator (model EP-3, Clinical Stimulator EPMed Systems).

Radiofrequency ablation was performed during atrial flutter in patients who presented in atrial flutter or during coronary sinus pacing at a cycle length of $600 \mathrm{msec}$ in patients who were in sinus rhythm. Radiofrequency energy was delivered along the isthmus as individual 60second applications at a target temperature of $60^{\circ} \mathrm{C}$ and a maximum power output of $50 \mathrm{~W}$ (model EPT-1000TC, EP Technologies).

Complete clockwise and counterclockwise isthmus block was confirmed by the analysis of the atrial activation sequence around the tricuspid annulus during pacing from the coronary sinus and posterolateral right atrium, and by the presence of widely split double potentials at all points along the ablation line. ${ }^{11}$ Complete bidirectional isthmus block also was confirmed with the presence of widely split double potentials along the entire ablation line during infusion of $2 \mu \mathrm{g} / \mathrm{min}$ of isoproterenol. ${ }^{14}$ Ablation was successful in 55 of 57 patients. Three patients required two procedures to achieve success.

\section{Study Protocol}

The counterclockwise transisthmus conduction interval was defined as the interval between the stimulus artifact and the local atrial activation recorded from the proximal coronary sinus electrode during pacing from the right atrium near the posterolateral tricuspid annulus (Fig. 2). The clockwise transisthmus conduction interval was defined as the interval between the stimulus artifact and the local atrial activation recorded from the pair of electrodes positioned on the isthmus just lateral to the ablation line during pacing from the distal electrode pair of the coronary sinus catheter (Fig. 3). Because conduction cannot occur through the isthmus after a line of complete block is created, the term transisthmus interval was used instead of transisthmus conduction time to describe the interval between the pacing stimulus and the local activation on the contralateral side of the ablation line, irrespective of the presence or absence of complete bidirectional block.

Twenty-eight of the 60 ablation procedures were performed during sinus rhythm. The transisthmus interval was determined in both the clockwise and counterclockwise directions during pacing at 500, 400, and $300 \mathrm{msec}$. During the remaining 32 ablation procedures, clockwise atrial flutter was present in 6 and counterclockwise atrial flutter was present in 26. In patients who presented in atrial flutter, the tachycardia was not terminated. Instead, atrial flutter was entrained by pacing at a cycle length 20 msec shorter $(243 \pm 34 \mathrm{msec})$ than the tachycardia cycle length $(263 \pm 34 \mathrm{msec})$. To entrain the atrial flutter, pacing was performed from the coronary sinus if the flutter was in the clockwise direction, and from the low right atrium if the flutter was in the counterclockwise direction. After the ablation, the transisthmus interval was measured at the pacing cycle length that was used to entrain the atrial flutter.

Transisthmus intervals were determined before any radiofrequency energy was applied and after complete bidirectional block was created. To accurately determine the longest possible transisthmus interval during incomplete block, transisthmus intervals also were measured during radiofrequency energy application immediately before a line of complete block was created (Figs. 3B and 4). Because radiofrequency energy was delivered during pacing from the coronary sinus in patients who had a period of incomplete block, transisthmus intervals during incomplete block were determined only in the clockwise direction. 
A

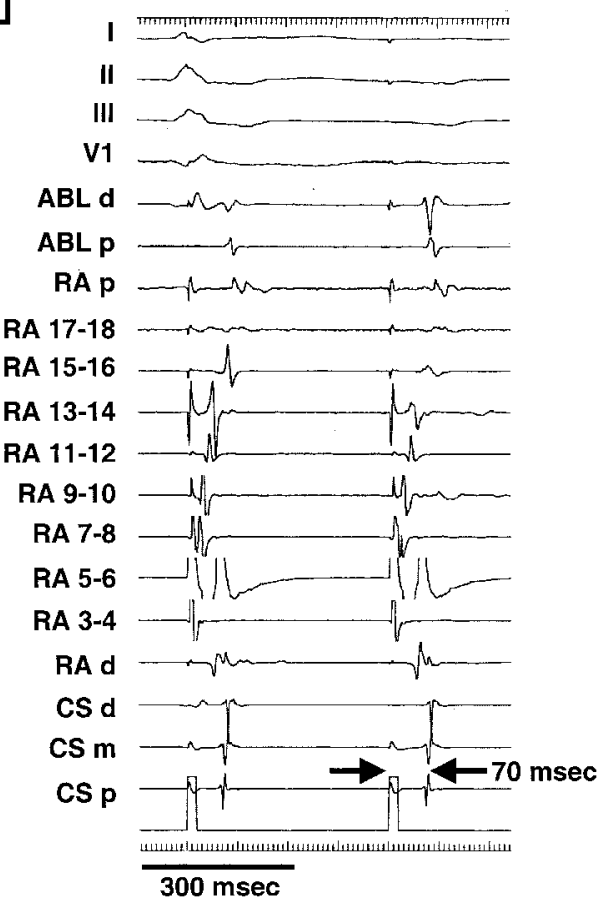

B
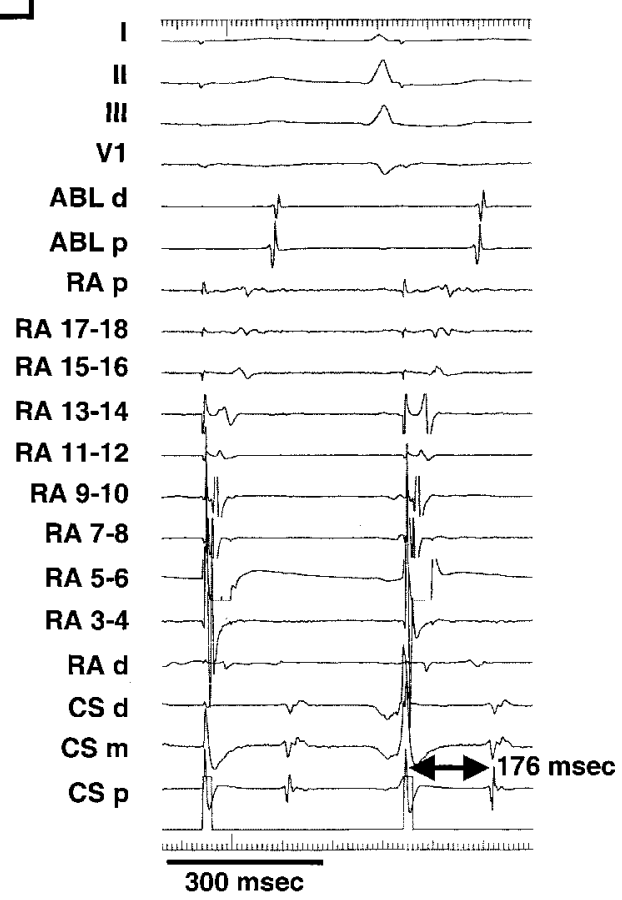

Figure 2. Measurement of counterclockwise transisthmus interval before (A) and after (B) complete transisthmus block. Surface ECG leads I, II, III, V1, and V5 and intracardiac electrograms from a duodecapolar halo (RAp-RAd), coronary sinus (CSd-CSp), and ablation (ABLd-ABLp) catheters are shown. The counterclockwise transisthmus interval was defined as the interval between the pacing artifact and the local atrial activation recorded from the proximal pair of electrodes on the coronary sinus catheter during pacing from the low right atrium.

A

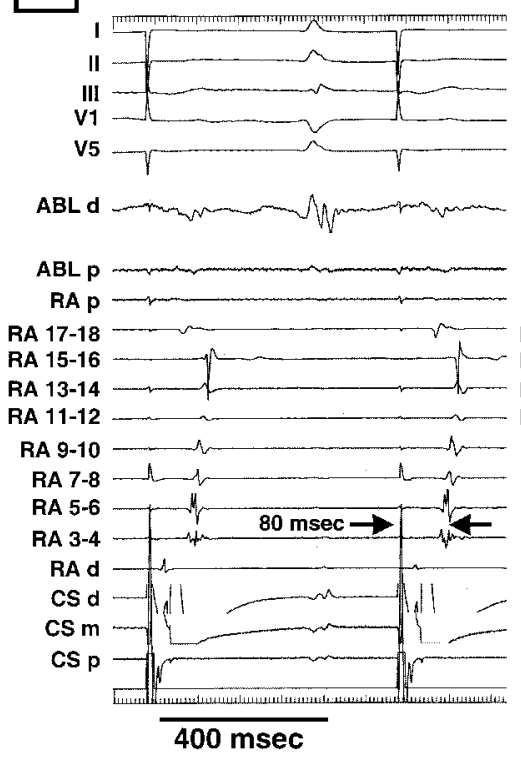

B
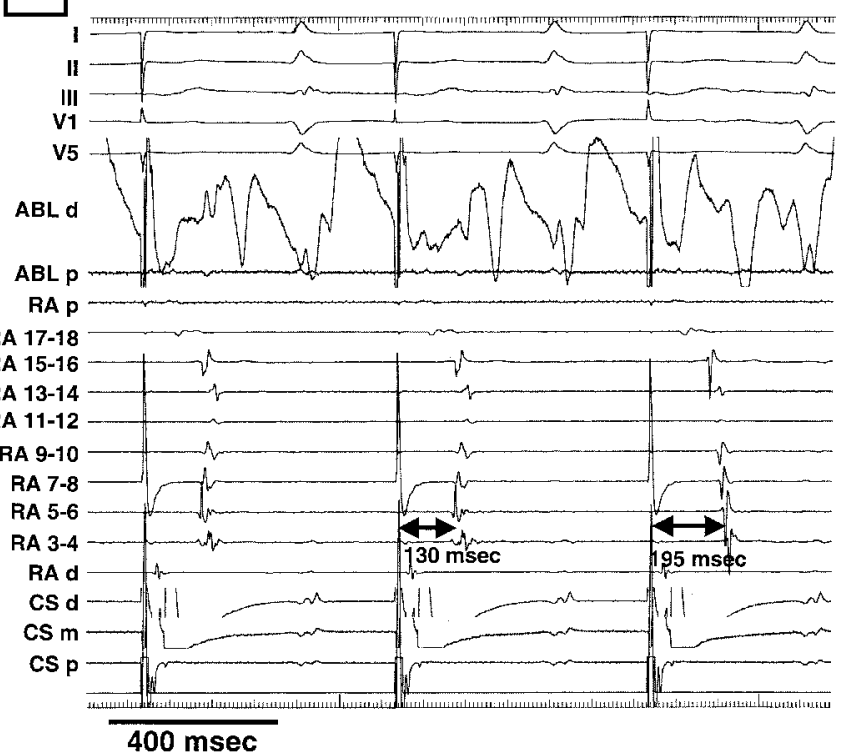

Figure 3. Measurement of the clockwise transisthmus interval. The clockwise transisthmus interval is measured from the pacing artifact to the local atrial activation recorded from the halo catheter on the contralateral side of the intended ablation line during pacing from the coronary sinus. (A) Transisthmus interval before the ablation. (B) Change in transisthmus intervals during radiofrequency energy application. The second beat shows a prolongation in the transisthmus interval without complete block. The third beat shows complete block. 


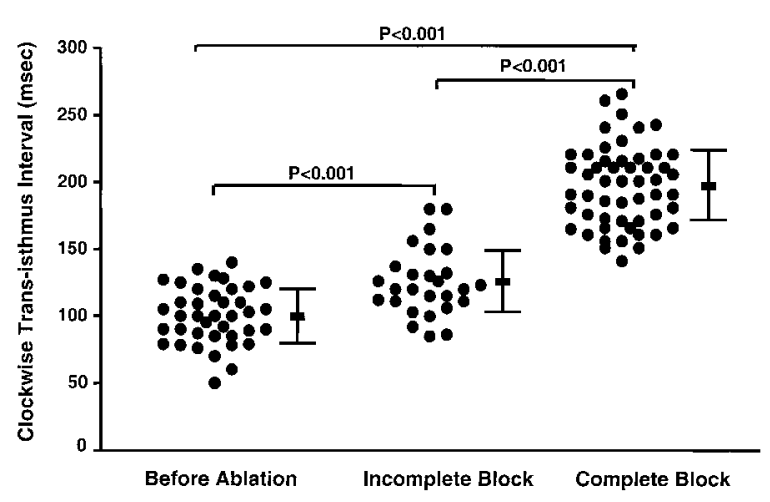

Figure 4. Transisthmus intervals before ablation, with incomplete block, and with complete block are shown.

\section{Statistical Analysis}

Continuous variables are expressed as mean \pm 1 SD. Differences between the transisthmus intervals before and after the ablation were detected with the paired $t$-test. Analysis of variance with repeated measures was used to compare the transisthmus intervals before ablation, during incomplete block, and after ablation. Post hoc analyses were performed with the Tukey test. $\mathrm{P}<0.05$ was considered statistically significant.

\section{Results}

\section{Transisthmus Intervals}

Transisthmus intervals before and after ablation are shown in Tables 1 and 2. After a successful ablation, the transisthmus intervals increased by $103 \% \pm 52 \%$ and $97 \% \pm 48 \%$ in the clockwise $(\mathrm{P}<0.001)$ and counterclockwise directions $(\mathrm{P}<0.001)$, respectively. Transisthmus intervals had decremental conduction properties in both directions before and after ablation $(\mathrm{P}<0.001$; Tables 1 and 2).

A period of incomplete isthmus block was observed during 28 (47\%) of the 60 ablation procedures (Figs. 3B and 4). In the remaining 32 procedures, complete line of block was created without a phase of incomplete block. The clockwise transisthmus interval during incomplete block $(127.5 \pm 25.9 \mathrm{msec})$ was $33 \% \pm 22 \%$ longer than the baseline transisthmus interval $(99.9 \pm 21.4 \mathrm{msec}$; $\mathrm{P}<0.0001)$ and significantly shorter than the transisth-

TABLE 1

Clockwise Transisthmus Intervals Before and After Ablation

\begin{tabular}{lccc}
\hline $\begin{array}{l}\text { Pacing Cycle } \\
\begin{array}{l}\text { Length } \\
\text { (msec) }\end{array}\end{array}$ & Before Ablation & After Ablation & P Value \\
\hline 500 & $99.0 \pm 22.0$ & $189.7 \pm 32.7$ & $<0.0001$ \\
400 & $102.0 \pm 22.7$ & $197.9 \pm 38.7$ & $<0.0001$ \\
300 & $106.6 \pm 24.9$ & $201.0 \pm 34.8$ & $<0.0001$ \\
$270 \pm 62$ & & & \\
(entrainment) & $99.5 \pm 23.3$ & $195.3 \pm 23.9$ & 0.003 \\
\hline
\end{tabular}

TABLE 2

Counterclockwise Transisthmus Intervals Before and After Ablation

\begin{tabular}{|c|c|c|c|}
\hline $\begin{array}{l}\text { Pacing Cycle } \\
\text { Length } \\
\text { (msec) }\end{array}$ & Before Ablation & After Ablation & $P$ Value \\
\hline 500 & $97.8 \pm 27.9$ & $177.7 \pm 31.1$ & $<0.0001$ \\
\hline 400 & $100.9 \pm 28.1$ & $182.2 \pm 31.8$ & $<0.0001$ \\
\hline 300 & $103.0 \pm 29.1$ & $181.6 \pm 31.2$ & $<0.0001$ \\
\hline $\begin{array}{l}240 \pm 30 \\
\quad \text { (entrainment) }\end{array}$ & $101.4 \pm 22.5$ & $194.3 \pm 35.2$ & $<0.0001$ \\
\hline
\end{tabular}

mus interval after complete bidirectional block was achieved $(188.1 \pm 34.5 \mathrm{msec} ; \mathrm{P}<0.0001)$.

\section{Predictive Value of Transisthmus Interval in Determining Complete Isthmus Block}

An increase in the clockwise transisthmus interval by $\geq 50 \%$, as compared with the baseline transisthmus interval, identified complete transisthmus block with $100 \%$ sensitivity, $80 \%$ specificity, $89 \%$ positive predictive value, $100 \%$ negative predictive value, and diagnostic accuracy of $92 \%$ (Figs. 4 and 5). All patients with complete bidirectional transisthmus block had $\geq 50 \%$ prolongation in the transisthmus interval when compared with the baseline transisthmus interval. No patient with $<50 \%$ prolongation in the counterclockwise or clockwise transisthmus interval had complete transisthmus block.

\section{Follow-Up}

After $130 \pm 89$ days (range 8 to 453 ) of follow-up, 2 patients $(5 \%)$ had a recurrence of atrial flutter at 8 and 93 days after the ablation procedure. Both of these patients had complete isthmus block at the conclusion of the initial ablation procedure. These two patients underwent a second ablation procedure, which showed transisthmus intervals that were either slightly longer (18\%) than, or similar to, the baseline transisthmus intervals before the first ablation, indicating recovery of transisthmus conduction. Complete bidirectional isthmus block was achieved in both of these patients after the second ablation procedure.

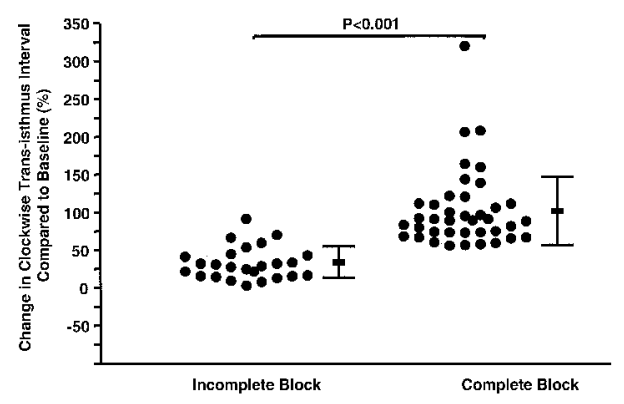

Figure 5. Ratio of transisthmus intervals during incomplete block and complete block to the baseline transisthmus intervals. 


\section{Discussion}

\section{Main Findings}

The major finding of this study is that a quantitative assessment of the transisthmus interval during atrial flutter ablation is a useful tool for identification of complete bidirectional block. No critical transisthmus interval appeared to discriminate between complete and incomplete bidirectional block in all patients. However, if the transisthmus interval increased by at least $50 \%$ in the clockwise direction, the diagnostic accuracy for complete block was $92 \%$, and the positive predictive value for identification of complete bidirectional block was $90 \%$. Similarly, complete bidirectional block of transisthmus conduction was not observed in any patient if the transisthmus interval did not increase by at least $50 \%$.

\section{Prior Studies}

No published study prospectively evaluated the discriminative power of a prolongation in the transisthmus interval in predicting complete bidirectional isthmus block in a large number of patients who underwent radiofrequency catheter ablation of atrial flutter. In this study, complete block was confirmed by the presence of a corridor of widely split double potentials along the ablation line and by a reversal in the atrial activation sequence, with and without infusion of isoproterenol. These validation criteria allowed for accurate differentiation of incomplete block and complete block.

Previous studies showed that transisthmus conduction times are prolonged after ablation..$^{12,13,15}$ However, a critical transisthmus interval to discriminate complete block from incomplete block was not identified. In the study by Tsai et al., ${ }^{15}$ a change $\geq 20 \mathrm{msec}$ in coronary sinus activation time from coronary sinus ostium to distal coronary sinus was reported to indicate complete block with a sensitivity of $96 \%$ and a specificity of $88 \%$. The diagnostic accuracy of this test was less than that of the present study. The present study and the study by Chen et al. ${ }^{13}$ found no overlap in transisthmus intervals before and after successful ablation. However, in the previous study, transisthmus intervals during incomplete block with slow conduction were not evaluated. ${ }^{13}$ Johna et al. ${ }^{12}$ reported that if the sum of the transisthmus intervals before and after the ablation was more than the flutter cycle length, there was complete isthmus block. In that study, it was assumed that the catheters were positioned exactly at the same locations before and after ablation, and that conduction velocity in the atrium was the same during flutter and pacing and was not affected by antiarrhythmic medications. The major limitation of each of these previous studies is that the current standard for identification of complete isthmus block, the presence of a corridor of widely split double potentials alongside the ablation line with and without infusion of isoproterenol, was not routinely performed. Therefore, it is possible that some of these patients did not have complete isth- mus block; this may have overestimated the value of these techniques. ${ }^{12,13,15}$

\section{Limitations}

This study has several limitations. First, there is no ideal method that can discriminate complete block from incomplete block with very slow conduction. However, at the present time, the presence of a corridor of widely split double potentials along the ablation line is the best technique to confirm complete bidirectional isthmus block because the recurrence rate is very low. ${ }^{11}$ Second, the transisthmus interval during incomplete block was assessed only in the clockwise direction. However, no case of unidirectional isthmus block was observed. In patients ablated during sinus rhythm, block in the counterclockwise direction was tested after complete clockwise block was demonstrated. Therefore, it is possible that an occasional patient may have had complete block in the counterclockwise direction before complete block was achieved in the clockwise direction. Third, efficacy of ablation was not prospectively evaluated based solely on the transisthmus intervals. Rather, the efficacy of ablation was initially monitored by the double potentials and a change in the atrial activation sequence. Fourth, some patients were taking antiarrhythmic medications at the time of the study. However, because transisthmus intervals were compared in each patient before and after the ablation, each patient served as his or her own control. The lack of statistical difference in baseline transisthmus intervals between patients who were taking antiarrhythmic agents and who were not may be due to the relatively small number of patients on antiarrhythmic agents.

\section{Conclusion}

Transisthmus intervals can be used to identify complete isthmus block with a very high diagnostic accuracy. A $<50 \%$ prolongation in the transisthmus interval always indicated incomplete block, and a $\geq 50 \%$ prolongation in the transisthmus interval indicated complete bidirectional block in $90 \%$ of patients. However, because a small number of patients with incomplete block and slow conduction can be misidentified as having complete block, the transisthmus interval should not be considered as the sole endpoint in ablation of atrial flutter. Rather, it is useful as a simple and quick initial indicator, requiring confirmation with other endpoints.

\section{References}

1. Feld GK, Fleck RP, Chen PS, Boyce K, Bahnson TD, Stein JB, Calisi CM, Ibarra M: Radiofrequency catheter ablation for the treatment of human type I atrial flutter. Identification of the critical zone in the reentrant circuit by endocardial mapping techniques. Circulation 1992;86:1233-1240.

2. Lesh MD, Van Hare GF, Epstein LM, Fitzpatrick AP, Scheinman MM, Lee RJ, Kwasman MA, Grogin HR, Griffin JC: Radiofrequency catheter ablation of atrial arrhythmias. Results and mechanisms. Circulation 1994;89:1074-1089. 
3. Fischer B, Haissaguerre M, Garrigues S, Poquet F, Gencel L, Clementy J, Marcus FI: Radiofrequency catheter ablation of common atrial flutter in 80 patients. J Am Coll Cardiol 1995;25:13651372.

4. Calkins H, Leon AR, Deam AG, Kalbfleisch SJ, Langberg JJ, Morady F: Catheter ablation of atrial flutter using radiofrequency energy. Am J Cardiol 1994;73:353-356.

5. Nakagawa H, Lazzara R, Khastgir T, Beckman KJ, McClelland $\mathrm{JH}$, Imai S, Pitha JV, Becker AE, Arruda M, Gonzalez MD, Widman LE, Rome M, Neuhauser J, Wang X, Calame JD, Goudeau MD, Jackman WM: Role of the tricuspid annulus and Eustachian valve/ridge on atrial flutter. Relevance to catheter ablation for the septal isthmus and a new technique for rapid identification of ablation success. Circulation 1996;94:407-424.

6. Schwartzman D, Callans DJ, Gottlieb CD, Dillon SM, Movsowitz $\mathrm{C}$, Marchlinski FE: Conduction block in the inferior vena cavaltricuspid valve isthmus: Association with outcome of radiofrequency ablation of type I atrial flutter. J Am Coll Cardiol 1996; 28:1519-1531.

7. Poty H, Saoudi N, Nair M, Anselme F, Letac B: Radiofrequency catheter ablation of atrial flutter: Further insights into the various types of isthmus block: Application to ablation during sinus rhythm. Circulation 1996;94:3204-3213.

8. Cauchemez B, Haissaguerre M, Fischer B, Thomas O, Clementy J, Coumel P: Electrophysiological effects of catheter ablation of inferior vena cava-tricuspid annulus isthmus in common atrial flutter. Circulation 1996;93:284-294.
9. Shah DC, Haissaguerre M, Jais P, Fischer B, Takahashi A, Hocini M, Clementy J: Simplified electrophysiologically-directed catheter ablation of recurrent common atrial flutter. Circulation 1997;96: 2505-2508.

10. Shah D, Haissaguerre M, Jais P, Takahashi A, Hocini M, Clementy J: High-density mapping of activation through an incomplete isthmus ablation line. Circulation 1999;99:211-215.

11. Shah DC, Takahashi A, Jais P, Hocini M, Clementy J, Haissaguerre M: Local electrogram-based criteria of cavotricuspid isthmus block. J Cardiovasc Electrophysiol 1999;10:662-669.

12. Johna R, Eckardt L, Fetsch T, Breithardt G, Borggrefe M: A new algorithm to determine complete isthmus conduction block after radiofrequency catheter ablation for typical atrial flutter. Am J Cardiol 1999;83:1666-1668.

13. Chen J, de Chillou C, Basiouny T, Sadoul N, Filho JD, MagninPoull I, Messier M, Aliot E: Cavotricuspid isthmus mapping to assess bidirectional block during common atrial flutter radiofrequency ablation. Circulation 1999;100:2507-2513.

14. Nabar A, Rodriguez LM, Timmermans C, Smeets JL, Wellens HJ: Isoproterenol to evaluate resumption of conduction after right atrial isthmus ablation in type I atrial flutter. Circulation 1999;99:32863291.

15. Tsai CF, Chen SA, Tai CT, Chiang CE, Yu WC, Chen YJ, Feng AN, Hsieh MH, Ding YA, Chang MS: Impact of transisthmus ablation of typical atrial flutter on coronary sinus activation time. PACE 2000;23:63-73. 